DA-1964, núm. 73. KARL ULE. La Ley de 21 de enero de 1960, reguladora de la jurisdicción c...

\title{
LA LEY DE 21 DE ENERO DE 1960, REGULADORA DE LA JURISDICCION CONTENCIOSO-ADMINISTRATIVA EN ALEMANIA
}

Por el Prof. KARL ULE

\begin{abstract}
Sumario: I. Evolución histórica.-II. Estructura de la Ley.-III. Contenido de la Ley.-1. Organización.-2. Ambito y extensión de la protección jurídica.-3. Intensidad de la protección jurídica.-4. Principios del procedimiento.-IV. Juicio critico.
\end{abstract}

I

A Ley de la Jurisdicción Contencioso-Administrativa constituye el precepto legal regulador de la constitución y el funcionamiento de los tribunales administrativos. La tutela juridica de tipo judicial, frente a los actos de la Administración, puede ser ofrecida por diversas instituciones. En los distintos paises del mundo se han puesto en práctica, sustancialmente, tres sistemas. Por ello pueden distinguirse, asimismo, tres ámbitos juridicos distintos:

1) El ámbito juridico anglosajón y escandinavo, dentro del cual los tribunales «ordinarios» conceden una protección juridica incluso frente a los actos de la Administración, si bien en Gran Bretaña, en los Estados Unidos de América y en otros paises pertenecientes a este campo, ganan progresivamente terreno, desde la primera guerra mundial, los llamados administrative tribunals, una especie de tribunales administrativos. 
DA-1964, núm. 73. KARL ULE. La Ley de 21 de enero de 1960, reguladora de la jurisdicción c...

2) El ámbito jurídico constituido siguiendo el ejemplo del Consejo de Estado francés, y que se extiende desde los paises latinos hasta los estados del Próximo Oriente y de Sudamérica, pasando por Bélgica, los Paises Bajos, Luxemburgo, Grecia y Turquia; en él, la protección jurídica se halla asegurada mediante una institución especial, el Consejo de Estado, al cual están encomendadas tareas de orden administrativo y jurisprudencial.

3) El ámbito juridico alemán (Alemania, Austria y en parte también Suiza) que ha evolucionado hasta la constitución de tribunales administrativos ajenos a la Administración, pero independientes también de los tribunales «ordinarios».

Para lograr una mejor comprensión de la vigente Ley reguladora de la Jurisdicción Administrativa, ofrecemos a continuación un breve resumen de la evolución experimentada por la jurisdicción administrativa alemana en los últimos cien años.

\section{Evolución histórica}

La jurisdicción administrativa, independiente de los poderes administrativo y judicial, no surgió en Alemania hasta la segunda mitad del siglo xIx, bajo la influencia de las ideas de Robert von Mohl y Rudolf von Gneist. La justicia administrativa (Verwaltungsrechtspflege o Administrativjustiz) que surgió en algunos Estados del centro y del sur de Alemania durante la primera mitad del siglo xIx obedecía al dechado del Consejo de Estado francés, y constituyó una parte integrante, de naturaleza orgánica, de la Administración y no del poder judicial. Esta justicia administrativa fué combatida duramente por los pensadores liberales partidarios del llamado Justizstaat, que dejaron constancia práctica de su punto de vista en el famoso parágrafo 182 de la Constitución Imperial de Frankfurt de 28 de marzo de 1849, que rezaba así: «Queda derogada la justicia administrativa; la decisión sobre cualesquiera violaciones de derechos compete exclusivamente a los tribunales.» Sin embargo, la evolución en los diversos Estados alemanes no siguió las normas señaladas por esta concepción. Los tribunales administrativos organizados en ellos desde 1863 (Baden) fueron separados de los tribunales ordinarios. En su instancia suprema (como, por ejemplo, en el «Tribunal Administrativo Superior» prusiano) se hallaban igualmente separados de la Administración. Pero en las instancias inferiores, tanto en Prusia como en la mayoría de los Länder alemanes, permanecieron ligados a las autoridades administrativas, desde el punto de vista no sólo orgánico, sino también 
DA-1964, núm. 73. KARL ULE. La Ley de 21 de enero de 1960, reguladora de la jurisdicción c...

personal, con objeto de cohonestar el principio de la descentralización administrativa de orden político con el de la tutela jurídica judicial. En algunos Estados del sur de Alemania, y sobre todo en Austria, surgió una jurisdicción administrativa de instancia única, faltando, por tanto, aquí la estrecha unión entre los órganos ejecutivos de la Administración y los tribunales administrativos. Esta diferencia guarda íntima relación con la diversidad de opiniones y teorias que existían en Prusia y en el sur de Alemania acerca de las tareas y cometidos propios de la jurisdicción administrativa: mientras que en el Estado primeramente citado dicha jurisdicción debía garantizar en primer término la legalidad (objetiva) de la Administración, en los restantes tenía como principal objeto la protección de los derechos subjetivos del individuo.

La protección juridica administrativa implantada durante los últimos decenios del pasado siglo en todos los Estados de mayor relevancia mediante el sistema de los tribunales administrativos, fué basada en Prusia, Baviera y la mayoria de los demás Estados en el llamado Enumerationsprinzip o principio enumerativo. La actuación de las autoridades administrativas sólo resultaba impugnable en vía administrativo-judicial, dentro de estos Estados, cuando la ley preveía especial y expresamente esta impugnación. Una generalidad jurídica parcial regia tan sólo para la impugnación de reglamentos de policia. En otros Estados, como, por ejemplo, en Württemberg, pero sobre todo en Austria, se hallaba en vigor, por el contrario, el principio de la generalidad, que aseguraba la protección jurídica administrativa frente a cualquier acto o medida adoptados por una autoridad administrativa.

El tránsito de la monarquía constitucional a la república democrático-parlamentaria no trajo consigo modificación alguna esencial en la configuración de la tutela juridica de tipo administrativo-judicial. La Constitución del Reich, promulgada en Weimar el 11 de agosto de 1919, no adoptó postura alguna frente al problema de la situación que habia de corresponder a la jurisdicción administrativa en relación con la Administración y con el poder judicial. Si bien declaraba en su artículo 107 que tanto en el Reich como en los Länder deberian organizarse, de acuerdo con las disposiciones contenidas en las leyes especiales, tribunales administrativos a quienes estaria encomendada la protección del individuo frente a las ordenanzas y disposiciones emanadas de las autoridades administrativas; pero nada decía acerca de si estos tribunales podian hallarse incorporados orgánicamente a la Administración o si, por el contrario, debían ser instituciones jurisdiccionales autónomas y separadas de ella. El «Tri- 
DA-1964, núm. 73. KARL ULE. La Ley de 21 de enero de 1960, reguladora de la jurisdicción c...

bunal Administrativo del Reich», previsto en esta disposición constitucional, no llegó a ser instituido durante la vigencia de la Constitución de Weimar.

El nacionalsocialismo no suprimió la jurisdicción administrativa como institución jurídica, pero la atacó en su misma entraña al suprimir su competencia en lo relativo a la impugnación de las medidas emanadas de los órganos de la policía estatal (supresión llevada a cabo ya en 1933), y finalmente al estimar como condición previa de la admisibilidad del procedimiento administrativo la aprobación del mismo por las autoridades administrativas. Al iniciarse la guerra, además, fueron suprimidos los Tribunales administrativos de Primera Instancia que funcionaban en Prusia, así como los correspondientes Tribunales administrativos de los Länder no prusianos. La creación, en el año 1943, del «Tribunal Administrativo del Reich», no introdujo modificación alguna en esta evolución, toda vez que vino a representar, pura y simplemente, la fusión de los tribunales administrativos y demás centros con facultades judiciales decisorias, tales como el «Tribunal Supremo Administrativo» (Oberverwaltungsgericht) de Prusia, la «Corte Disciplinaria del Reich» (Reichsdienststrafhof), el «Tribunal Económico-Administrativo del Reich» (Reichswirtschaftsgericht), la «Corte Suprema Administrativa (Verwaltungsgerichtshof) de Viena, la «Comisión Suprema Sentenciadora de Aplazamientos» (Oberste Spruchstelle für Umlegungen) y la «Comisión Suprema Sentenciadora de Gremios de Tierras y Aguas (Oberste Spruchstelle für Wasser- und Bodenverbände), el «Tribunal de Indemnizaciones» (Entschädigungsgericht) y la «Oficina Central del Reich para Daños de Guerra» (Reichskriegsschädenamt).

Tras el hundimiento del Estado nacionalsocialista, los Tribunales administrativos que funcionaban a la sazón, tanto en el Reich como en los Länder, fueron disueltos de inmediato por disposición de las potencias ocupantes. No obstante, su reapertura, asi como los trabajos previos conducentes a la reorganización legal de la jurisdicción administrativa, de acuerdo con los principios del Estado de Derecho, se iniciaron ya en el mismo año 1945. En el otoño de 1956 se promulgó en los tres Länder correspondientes a la zona americana de ocupación (esto es, Baviera, Hessen y Baden-Württemberg), la Ley sobre Jurisdicción Administrativa, que en el verano de 1947 fué introducida asimismo en Bremen. En virtud de una disposición del Goblerno militar británico, que llevaba el número 165 , se reglamentó en septiembre de 1948 la jurisdicción administrativa en todo el territorio de ocupación inglesa. Tras de implantarse, entre 1946 y 1947, la nueva reglamentación legal de la jurisdicción administrativa en los Länder 
DA-1964, núm. 73. KARL ULE. La Ley de 21 de enero de 1960, reguladora de la jurisdicción c...

de Württemberg-Hohenzollern y de Baden, se dió asimismo nueva regulación legal a dicha jurisdicción en Rheinland-Pfalz (año 1950) y en Berlín y el territorio del Sarre (1951), siguiendo las huellas de la legislación implantada en las zonas de ocupación británica y americana. El año 1958, Baden-Württemberg ha reunido y refundido en una ley unitaria las diversas disposiciones que se hallaban vigentes en su territorio.

Por imperativo del articulo 96, párrafo primero de la Ley Fundamental, incumbe al Poder Legislativo Central la tarea de instituir un Tribunal Federal superior que detente la jurisdicción administrativa general. El legislador ha dado cumplimiento a este cometido mediante la Ley reguladora del «Tribunal Administrativo Federal» (Bundesverwaltungsgericht), de 23 de septiembre de 1952 . Compete asimismo al Estado Federal la legislación relativa a la organización de la jurisdicción administrativa y al procedimiento a seguir ante los Tribunales administrativos de los Länder (art. 74, núm. 1 de la Ley Fundamental). El Estado Federal ha hecho uso de esta competencia mediante la promulgación de la Ley reguladora de la Jurisdicción Administrativa (Verwaltungsgerichtsordnung, en siglas VwGO.), de 21 de enero de 1960. Mediante ella ha venido a subsanarse la dispersión en la regulación legal de la tutela juridica administrativa, reglamentada hasta el presente por la Ley sobre el Tribunal Administrativo Federal y, además, por siete leyes de otros tantos Länder, asi como por la Orden número 165 del Gobierno militar británico de ocupación (MRVO). La Ley reguladora de la Jurisdicción Administrativa rige exclusivamente para la jurisdicción administrativa general o común. Junto a ella existen jurisdicciones administrativas especiales, tales como la jurisdicción de Hacienda y la jurisdicción laboral o social; el procedimiento ante los tribunales de estas ramas jurisdiccionales es objeto de regulación en leyes especiales.

\section{Estructura de la Ley}

La Ley de Jurisdicción Administrativa se divide en cinco partes, que son las siguientes: Parte I: «Organización de los Tribunales»; Parte II: «Procedimiento»; Parte III: «Recursos y reapertura del procedimiento»; Parte IV: «Costas y ejecución»; Parte V: «Disposiciones finales y disposiciones transitorias». Cada una de estas partes, a excepción de la $\mathrm{V}$, se halla subdividida en capitulos, que detallamos a continuación. Parte I: «Tribunales», «Jueces», «Jueces administrativos honorificos», «Representantes del interés público», «Administra- 
DA-1964, núm. 73. KARL ULE. La Ley de 21 de enero de 1960, reguladora de la jurisdicción c...

ción judicial», «Vía judicial administrativa» $\mathrm{y}$ «Competencia»; en total, seis capitulos. Parte II: comprende los cinco siguientes: «Principios generales del procedimiento», «Preceptos especiales sobre la Acción pauliana y Acciones obligacionales», "Procedimiento en primera instancia», «Sentencias y otras resoluciones», «Disposiciones prorisionales»; Parte III: comprende los cuatro siguientes: «Apelación». «Revisión», «Recurso de queja» y «Reapertura del procedimiento»; Parte IV: incluye los dos capitulos siguientes: «Costas» $y$ «Ejecución». Como ya hemos dicho, la Parte V no se halla subdividida en capítulos; no obstante, en este título se of rece una importante ampliación complementadora de la Ley de Introducción a la Orgánica del Poder Judicial (Einführungsgesetz zum Gerichtsverfassungsgesetz), (parágrafo 179 de la VwGO), sobre la que hablaremos más adelante en el apartado III, número 1 de este trabajo.

\section{Contenido de la Ley}

\section{Organización}

La organización de la Jurisdicción administrativa general o común se divide en tres grados, a saber:

a) Tribunales Administrativos.

b) Tribunales Administrativos Superiores (llamados, en los Länder del sur de Alemania, Verwaltungsgerichtshöfe), y

c) Tribunal Administrativo Federal.

A) Los Tribunales administrativos poseen competencia material para conocer de cuantas demandas sean admisibles dentro de la vía jurisdiccional administrativa.

B) Los Tribunales Administrativos Superiores son, sustancialmente, Tribunales de apelación $y$ de queja, no obstante lo cual puede competirles asimismo el control de los preceptos juridicos de rango inferior a ley, emanados de los Ländzr, en el llamado Normenkontrolle (parágrafo 47 de la VwGO).

C) Por último, el Tribunal Administrativo Federal es (prescindiendo de escasas excepciones, en las que funciona con el carácter de Tribunal de primera instancia) un Tribunal de revisión y casación.

A) Los Tribunales Administrativos están constituidos por tres Magistrados (profesionales) y dos Jueces administrativos honorificos.

B) Los Tribunales Administrativos Superiores (salvo divergencias 
DA-1964, núm. 73. KARL ULE. La Ley de 21 de enero de 1960, reguladora de la jurisdicción c...

Estudios

impuestas por los derechos locales de los Länder) lo están por tres Jueces (asimismo profesionales), y

C) El Tribunal Administrativo Federal, por cinco Jueces profesionales.

Los Jueces de la Jurisdicción administrativa deberán poseer la califlcación profesional activa para el desempeño de la carrera judicial; la ley no exige otras condiciones, como, por ejemplo, la posesión de una determinada experiencia administrativa. Todos ellos gozan, tanto en el aspecto personal como material, de las garantias y prerrogativas de la independencia judicial.

Existen Tribunales administrativos en todos los Länder federales. En los que cuentan con autoridades estatales de rango intermedio, la sede es por lo general la de éstas, abarcando la demarcación o el distrito de un Presidente de Gobierno local (Presidencia del Gobierno, Regierungspräsidium). La mayoria de los Länder poseen asimismo un Tribunal Administrativo Superior propio; no obstante, los Länder de Baja Sajonia y Schleswig-Holstein cuentan con un Tribunal Administrativo Superior común para ambos, que tiene su sede en Lüneburg.

\section{AMBITO Y EXTENSIÓN DE LA PROTECCIÓN JURÍDICA}

La admisibilidad de la via administrativa se halla determinada por el principio de la generalidad (Generalklausel). Desde luego, la Ley Fundamental (contrariamente a las Constituciones de algunos Länder) no contiene garantia alguna de orden juridico-constitucional en favor de dicha «cláusula general», pero la disposición contenida en el artículo 19, párrafo 4, frase 2 de la Ley Fundamental surte, de hecho, los efectos de tal garantia, ya que cualquier limitación legal del principio de la generalidad fundamentaria de modo automático la admisibilidad de la vía jurisdiccional ordinaria. Esta reglamentación fegal viene a confirmar la importancia del principio de la generalidad para el ordenamiento - propio de un Estado de Derechoque estableció la Ley Fundamental.

La citada «cláusula general» consiste, en esencia, en que todo litigio de orden juridico-administrativo (el parágrafo 40 , párrafo 1 de la VwGO habla de litiglos jurídico-públicos de naturaleza ajena al orden juridico-constitucional) puede ser incoado ante los Tribunales administrativos. La competencia procesal de la jurisdicción ordinaria y de la jurisdicción administrativa depende sustancialmente de que el objeto del litigio posea naturaleza jurídico-privada $o$ bien juridico-administrativa; no obstante, la legislación puede imponer 
DA-1964, núm. 73. KARL ULE. La Ley de 21 de enero de 1960, reguladora de la jurisdicción c...

excepciones que vengan a quebrantar este principio general (parágrafo 40, párrafo 1 de la VwGO). Así, la Ley Fundamental encomienda a los tribunales ordinarios las acciones de indemnización por expropiación forzosa (artículo 14, párrafo 3) y las acciones por daños provenientes del incumplimiento de los deberes oficiales (art. 34). Tales «asuntos procesales civiles en virtud de asignación legal» incluyen asimismo, según el parágrafo 40 , párrafo 2 de la VwGO, las acciones patrimoniales como consecuencia de sacrificios sufridos en aras del bien común y de depósitos de origen y naturaleza juridicopública, así como las acciones por daños originados por la violación de deberes jurídico-públicos. Muchos otros casos pueden hallarse en numerosas leyes del Reich, de la República Federal y de los Länder. La misma Ley de Jurisdicción Administrativa contiene un precepto de excepción, de importancia fundamental: en su parágrafo 179 abre la via jurisdiccional ordinaria (en este caso, los Tribunales Superiores de cada Land) a la impugnación procesal de determinados actos de la Administración de Justicia. También aqui se concede una protección jurídico-administrativa a través de la jurisdicción ordinaria. Por el contrario, las acciones juridico-patrimoniales de los funcionarios públicos (tanto del Gobierno Federal como de los Länder), que antaño sólo tenian cabida dentro de la via jurisdiccional ordinaria, pueden ser mantenidas ahora en la vía administrativa (parágrafo 127 del Estatuto de Funcionarios, o Beamtenrechtsrahmengesetz, en siglas BRRG). La competencia (existente según la jurisprudencia del Tribunal Supremo del Reich y de la Corte Suprema Federal de Justicia) de los tribunales ordinarios en los litigios juridico-administrativos, «en virtud de la tradición», y que ha sido constantemente negada por la doctrina juridica administrativa y por la jurisprudencia de los Tribunales Administrativos desde la publicación de las leyes administrativo-jurisdiccionales posteriores a la segunda guerra mundial, ha sido definitivamente suprimida por la Ley sobre Jurisdicción Administrativa vigente. Las cuestiones de competencia entre tribunales de las diversas jurisdicciones se hallan reglamentadas de tal manera que los conflictos de competencia afirmativa quedan excluidos por obra $y$ virtud del principio de la interrelación mutua, y los conflictos negativos por las posibilidades de remisión de una via jurisdiccional a otra (parágrafo 41 de la VwGO).

Dentro del sistema de la protección juridica administrativo-judiclal desempeña hoy todavía un papel sobresaliente la acción pauliana (Anfechtungsklage), que era caracteristica de la jurisdicción administrativa de antaño. Puede ejercitarse dicha acción contra los actos dañosos emanados de la Administración en uso de sus facultades 
DA-1964, núm. 73. KARL ULE. La Ley de 21 de enero de 1960, reguladora de la jurisdicción c...

discrecionales, mientras que la exención de los actos administrativos favorables puede ser instada mediante la acción obligacional. .Esta puede ser incoada asimismo cuando la autoridad administrativa no ha adoptado todavía una decisión acerca de la reclamación contra un acto emanado de la Administración (la llamada Untätigkeitsklage o acción de inactividad). De aquí se deduce la notable importancia que corresponde al concepto de acto administrativo, incluso en la más reciente jurisdicción administrativa alemana. $Y$ es que, en efecto, sólo los actos administrativos, pero al mismo tiempo todos los actos administrativos sin excepción (ya que dentro de un ordenamiento político estrictamente jurídico no pueden existir los actos administrativos absolutamente discrecionales, esto es, libres o exentos de impugnación judicial) pueden ser impugnados mediante la acción pauliana.

La Ley sobre Jurisdicción Administrativa no contiene una definición del acto administrativo. Este concepto es una creación de la doctrina. Según la famosa definición de Otto Mayer, el acto adminiștrativo es una «decisión autoritaria emanada de la Administración, que determina en cada caso. concreto lo que es ley para el súbdito». Según la definición legal contenida en la disposición número 165 del Gobierno militar británico, ya citada (parágrafo 25, apartado. 1), un acto administrativo era «toda disposición, ordenanza, decisión $\mathrm{u}$ otra medida cualquiera adoptada por una autoridad administrativa para regular juridicamente un caso concreto dentro del ámbito del Derecho público». Las leyes, las disposiciones legales y otros preceptos juridicos no pueden ser, por ello, ni actos de la Administración ni sentencias o decisiones judiciales. Mas también las medidas de hecho adoptadas por la Administración, si son puramente de hecho, caen fuera del concepto de acto administrativo. La medida, para ser un verdadero acto administrativo, ha de poseer el efecto jurídico de reglamentar un caso concreto dentro del ámbito del Derecho público. Puede en ocasiones (como es caso frecuente en el Derecho administrativo económico) aparecer bajo la vestidura de un negocio juridico de naturaleza privada. El concepto de acto administrativo se halla aqui, pues, determinado plenamente a partir de su contenido. Por ello mismo, los actos administrativos en el sentido de la Ley de Jurisdicción Administrativa son asimismo medidas que adopta la Administración en relaciones especiales coercitivas $u$ obligatorias vinculantes. Dichas relaciones especiales coercitivas o de fuerza son, ante todo, la relación juridica del funcionario público y la del servicio militar obligatorio, así como todas las relaciones institucionales, y en especial la relación o situación escolar. Siempre que las medidas concretas adoptadas en 
DA-1964, núm. 73. KARL ULE. La Ley de 21 de enero de 1960, reguladora de la jurisdicción c...

ellas por la Administración vẻngan a regular las relaciones jurídicas relativas al fundamento, la modificación o el término de la relación coercitiva, se tratará de actos administrativos; por el contrario, se discute por la doctrina si acaso también las medidas que atañen no a la relación esencial, sino a las relaciones funcionales o de servicio (Betriebsverhältnis); esto es, derivadas de la validez de los (escritos o no escritos) «reglamentos orgánicos» o normas de funcionamiento, tanto en el servicio público como en los establecimientos de carácter público, han de ser consideradas como actos administrativos.

\section{INTENSIDAD DE LA PROTECCIÓN JURIDICA}

a): El principio de la generalidad delimitá, sí, el ámbito de la tutela jurídica administrativo-jurisdiccional, pero deja en pie la cuestión de su intensidad. El Derecho vigente antes de la promulgación de la Ley reguladora de la Jurisdicción Administrativa había limitado ya la tarea de los Tribunales administrativos, sustancialmente, a la decisión de cuestiones de derecho. La Ley actualmente vigente ha venido a suprimir del todo las escasas excepciones que todavia subsistían, expresando con toda claridad que los Tribunales administrativos se limitarán a sentenciar los litigios de tipo contencioso (parágrafo 40, párrafo.1) motivados por las acciones paulianas o de tipo obligacional acerca de la legalidad o la antijuridicidad del acto adminịstrativo que se impugna, o bien de su recusación u omisión (parágrafo 113, párrafios 1 y 4), pero no sobre su pertinencia o su inoportunidad. Estando capacitadas las autoridades administrativas para actuar con arreglo a su libre discrecionalidad, los Tribunales administrativos no están autorizadọs para imponer su discrecionalidad en lugar de la de las autoridades administrativas. En los actos discrecionales; los Tribunales administrativos sólo pueden examinar la legalidad de las medidas o su carácter contrario a Derecho, pero no su oportunidad o inoportunidad. Un acto administrativo contrario a Derecho acaece, por ello, en estos casos tan sólo cuando se traspasan los limites legales de la discrecionalidad o bien cuando se hace uso de ésta de forma no adecuada al fin previsto de la autorización (parágrafo 114 de la Ley).

b) La verdadera problemática de la intensidad de la protección jurídica administrativo-judicial radica, empero, más allá de esta regulación legal. En realidad, no existe una intrusión (objetada por algunos criticos de la moderna jurisdicción administrativa) de los Tribunales administrativos en el ámbito discrecional de la Administración; antes al contrario, trátase en realidad de la cuestión de si 
DA-1964, núm. 73. KARL ULE. La Ley de 21 de enero de 1960, reguladora de la jurisdicción c...

Estudios

los Tribunales administrativos, en la aplicación de ciertos conceptos jurídicos indeterminados (tales como admisibilidad, necesidad, interés público, etc.) por parte de las autoridades administrativas, pueden compulsar esta aplicación en su totalidad. Tanto la doctrina como la jurisprudencia eran antes de la opinión de que los conceptos legales indeterminados debían ser definidos de modo unívoco, al igual que los restantes conceptos jurídicos, y también que los Tribunales administrativos podían, por ello mismo, examinar y compulsar plenamente su interpretación y aplicación al caso concreto y determinado. La novísima evolución juridica se mueve en la dirección que afirma que aqui se ha impuesto un limite al examen y compulsión de los Tribunales administrativos, derivado de la esencia misma de los conceptos jurídicos indeterminados (Gesetz es begriffe) como conceptos normativos (Karl Hermann Ule), o bien del «ámbito de enjuiciamiento» que les era propio (Otto Bachof). Según esta doctrina, los conceptos juridicos indeterminados admiten en ciertos casos límites diversas decisiones o resoluciones, todas ellas de validez juridica idéntica. Siempre que la resolución de la autoridad administrativa sea defendible dentro del marco del concepto legal indeterminado o ambiguo, el Tribunal administrativo deberá reconocer dicha resolución como conforme a derecho.

Parecidos límites se imponen a los Tribunales administrativos en el examen y compulsa de juicios de valor de carácter pedagógico o científico. Tales juicios, según opinión aceptada hoy generalmente, no son resoluciones discrecionales o facultativas, ya que en ellos no es posible hablar de una verdadera elección entre varias resoluciones posibles juridicamente equivalentes. Pese a ello, no son compulsables por la via jurisdiccional administrativa porque, en cuanto prestaciones insustituibles, están sustraidas a la prueba técnica suplementaria mediante el Tribunal, ni siquiera con el auxilio de peritos. En consecuencia, sólo podrán ser examinados en lo relativo a si, tanto sea en el aspecto material como en el formal, han sido adoptados de modo válido e incontestable.

\section{PRINCIPIOS DEL PROCEDIMIENTO}

a) Si bien la acción pauliana, dentro del sistema de tutela juridica administrativo-judicial, juega hoy dia también un importante papel, ha perdido el puesto predominante que logró alcanzar en la anterior regulación legal y práctica de la jurisdicción administrativa. Desde luego, la importancia práctica de la acción declaratoria, que se dio antiguamente en algunos Länder (Hamburgo, Bremen, Mec- 
DA-1964, núm. 73. KARL ULE. La Ley de 21 de enero de 1960, reguladora de la jurisdicción c...

klenburgo-Strelitz), es relativamente escasa, aunque sin duda, según sostienen las doctrinas más recientes y discutidas (Richard Naumann) habrá de atribuírsele una importancia notablemente mayor como acción declaratoria preventiva, pero junto a la acción pauliana ha surgido, sobre todo, la acción de prestación o ejecución (Leistungsklage), cuyas diversas formas procesales han venido a transformar decisivamente la imagen tradicional de la jurisdicción administrativa alemana. La acción pauliana del Derecho anterior y del vigente es, en realidad, una acción de transformación. Con ella se pretende una sentencia en virtud de la cual se anule o revoque, por antijurídico, un acto administrativo. Con la acción de prestación, por el contrario, puede pretenderse la condena a una acción, a un consentimiento o a una abstención, y por ello mismo también, en determinadas circunstancias, a la omisión o abstención de un acto oficial. Una forma especial de la acción de prestación la constituye la acción obligacional (Verpflichtungsklage), con la cual se pretende la condena de una autoridad administrativa a la ejecución de un acto administrativo omitido o interrumpido. Posee especial importancia en los campos de la Administración, en los cuales el individuo precisa de una autorización o una concesión especial para emprender una actividad determinada, como, por ejemplo, una profesión o un oficio. Su ámbito de aplicación está constituido sobre todo por el campo de las prestaciones administrativas, tales como, por ejemplo, el Seguro social. Dada la actual y estricta sujeción a las leyes de esta Administración de prestaciones, que sólo deja campo libre para las decisiones discrecionales de las autoridades administrativas en casos de excepción, la acción obligacional ha desplazado aqui casi por completo a la acción pauliana. Otro género de la acción de prestación es la acción que se dirige de modo inmediato a la obtención del pago de cantidades dinerarias. Gracias a la remisión de las pretensiones juridico-patrimoniales de los funcionarios a la via jurisdiccional administrativa, ha conservado un amplio ámbito de utilización.

b) En todos estos tipos de acciones, la admisibilidad de las mismas precisa, como requisito previo, la existencia de la necesidad de tutela juridica por parte del demandante. En la acción declarativa, el demandante deberá ostentar un interés justificado en la consiguiente sentencia declarativa (parágrafo 43 de la Ley), y en la acción de prestación habrá de hacer valer una pretensión propia. En la acción pauliana y en la acción obligacional ha de verse lesionado en sus derechos legitimos por el acto administrativo concreto o por su omisión (parágrafo 42 , párrafo 2 de la Ley). La legitimación, pues, para interponer la demanda, no la ostenta todo aquel que estime contrario 
DA-1964, núm. 73. KARL ULE. La Ley de 21 de enero de 1960, reguladora de la jurisdicción c...

a derecho un acto administrativo cualquiera. La acción popular es una institución ajena a la jurisdicción administrativa alemana. Se discute incluso si también las asociaciones, singularmente las de tipo económico o profesional, pueden formular una demanda en nombre de uno de sus miembros, lesionado por el acto administrativo; la opinión predominante en la doctrina y en la jurisprudencia se inclina hasta el presente por rechazar esta ampliación de la potestad para demandar.

c) El procedimiento en la jurisdicción administrativa se asemeja sustancialmente al proceso civil. Aunque la Ley sobre Jurisdicción Administrativa evita el empleo del concepto de partes procesales para designar al actor y al demandado, el proceso está configurado como proceso contradictorio de partes. Se diferencia del proceso civil, fundamentalmente, en la necesidad de la existencia de diligencias presumariales administrativas en las acciones pauliana y obligacional, así como también en el predominio del principlo inquisitivo o de instrucción, que encomienda al Tribunal, y no a las partes, la tarea de investigación y determinación de las cuestiones de hecho. No existe, por ello mismo, una carga subjetiva de la prueba o de producción de la prueba, y sí en cambio una carga objetiva, porque es necesario reglamentar cuál de ambas partes ha de sufrir las consecuencias de la falta de prueba cuando la solicitada por las partes o la practicada de oficio por el Tribunal no han conducido a resultado práctico alguno. Tanto la doctrina como la jurisprudencia discuten a cuál de las partes incumbe la carga de la prueba en la acción pauliana. Según la opinión predominante y más acertada, la autoridad administrativa deberá probar que concurren los presupuestos de hecho, en los cuales descansa la juridicidad del acto administrativo por ella ejecutado, y no, a la inversa, el demandante, quien habrá de probar que no han concurrido dichos presupuestos, si se trata de una acción pauliana. Por el contrario, tratándose de una acción obligacional será el actor quien deberá probar la existencia de los presupuestos de hecho, de los cuales deriva él su demanda en contra del acto administrativo que trata de impugnar. Caso de que, en la acción pauliana, se resolviese de otro modo, la falta de claridad del contenido material o cuestión de hecho sobre el que se basa el acto administrativo impugnado conduciria al mantenimiento en vigor de dicho acto; sin embargo, tan ventajosa superioridad de la Administración frente al ciudadano no resulta muy conciliable ni con la estructura político-juridica de nuestra nación, en general, ni con la del proceso administrativo, en particular.

d) El procedimiento ante los Tribunales Administrativos de pri- 
DA-1964, núm. 73. KARL ULE. La Ley de 21 de enero de 1960, reguladora de la jurisdicción c...

mera instancia concluye normaimente con una sentencia, si no es retirada antes la demanda o terminado el litigio por otros medios, como, por ejemplo, mediante revocación del acto administrativo o mediante transacción. Las sentencias de los Tribunales Administrativos son, en esencia, impugnables mediante apelación ante el Tribunal Administrativo Superior; no obstante, la apelación puede ser declarada dependiente de una autorización especial, mediante ley federal si se trata de determinadas esferas juridicas o bien mediante leyes locales de los Länder tratándose de esferas concretas de Derecho local de cada Land y siempre que no esté limitado ya, en este caso, por una ley federal; sin embargo, esta dependencia o limitación lo será sỏlo por una duración máxima de cinco años (parágrafo 131, párrafo 1 de la Ley). Contra las sentencias de los Tribunales Administrativos Superiores se da el recurso de revisión ante el Tribunal Administrativo Federal, recurso necesitado de autorización especial, excepto cuando se basa en la existencia de defectos que invaliden el procedimiento (parágrafo 133 de la Ley). La autorización necesaria para el recurso de revisión sólo prosperará cuando la cuestión de derecho es de importancia fundamental o cuando la sentencia difiere en lo esencial de una resolución dictada por el Tribunal Administrativo Federal y se basa precisamente en esta divergencia; o bien, en un defecto de procedimiento denunciado en forma y tiempo, la resolución impugnada puede fundamentarse precisamente en este defecto procesal (parágrafo 132, párrafo 2 de la Ley). Contra la denegación del recurso de revisión puede interponerse recurso de queja. La revisión sólo podrá basarse en la violación de un precepto legal de ámbito federal por parte de la sentencia impugnada. La violación de derechos locales no puede, pues, ser atacada mediante el recurso de revisión. En las cuestiones juridicas de ámbito local, la via de recursos termina, por tanto (prescindiendo de los litigios derivados del derecho y condición de funcionario público, según el parágrafo 127 del Estatuto de Funcionarios), en el Tribunal Administrativo Superior.

e) Para la efectividad de la tutela jurídica administrativo-judicial no se requiere meramente que el particular lesionado por una medida o acto de la Administración disponga de suficientes posibilidades procesales de acción y de un procedimiento provisto de las necesarias garantías juridicas. Idéntica importancia posee la cuestión de si las autoridades administrativas, dentro del ámbito de la facultad discrecional, pueden verse impedidas para crear hechos consumados antes de que recaiga resolución sobre la demanda, y si, en el ámbito de las prestaciones administrativas, pueden ser compelidas a adoptar me- 
DA-1964, núm. 73. KARL ULE. La Ley de 21 de enero de 1960, reguladora de la jurisdicción c...

didas provisionales. El efecto fundamentalmente dilatorio de la contradicción (dentro del procedimiento previo o diligencias presumariales administrativas) y de la acción pauliana, la implantación y el restablecimiento del efecto dilatorio de estos recursos legales por el mismo Tribunal, en los casos en que no concurre este efecto dilatorio por obra de una disposición legal o una orden de la autoridad, y la revocación de la ejecución en los actos administrativos ya consumados (parágrafo 80 de la Ley) impiden que se ejecute un acto administrativo, 0 bien que permanezca sin revocar $o$ anular, antes de que haya recaido una decisión sobre su conformidad o disconformidad con la ley. Esta disposición rige asimismo, por lo que respecta a los actos administrativos modiflcadores de una situación legal, tales como, por ejemplo, los expedientes de despido de los funcionarios. En las acciones de prestación o ejecución, el Tribunal, mediante acuerdo provisional, puede inducir a las autoridades administrativas a dictar disposiciones asimismo provisionales (art. 123 de la Ley). También ha de citarse, a este respecto, la posibilidad de emplear medios coercitivos para obligar a la Administración a realizar un acto administrativo, a cuya ejecución ha sido condenada (parágrafo 172 de la Ley).

\section{Juicio crítico}

La tutela jurídica administrativa existente en la actualidad en la República Federal a través de la Ley sobre Jurisdicción Administrativa satisface, tanto por su estructuración orgánica, por su amplitud y por las garantías procesales que ofrece, todas las exigencias que pudieran serle formuladas desde la mentalidad propia del Estado de Derecho. Sin embargo, también halla defensores la opinión de que la legislación, en algunos casos aislados, como, por ejemplo, en la estructuración de la triple instancia procesal, se ha propasado de su verdadera finalidad, porque la duración del procedimiento a ella ligado redunda desfavorablemente en la eficacia práctica de la protección jurídica. De modo patente se ha tomado aqui como modelo la organización de la jurisdicción ordinarià, si bien las peculiaridades propias del procedimiento administrativo, que se apoya en un procedimiento previo administrativo de una sola o de doble instancia, hubiesen permitido otra solución.

Aunque la Ley intenta eliminar innumerables cuestiones dudosas o debatidas existentes en el derecho vigente hasta ahora, lo cierto es que no adopta ninguna posición, ni expresa ni tácita, frente a muchos e importantisimos problemas de Derecho procesal adminis- 
DA-1964, núm. 73. KARL ULE. La Ley de 21 de enero de 1960, reguladora de la jurisdicción c...

trativo. Pertenecen a estos problemas, por ejemplo, las cuestiones constitucionales de orden judicial de la pertenencia a una sección o jurisdicción, de la inspección judicial, de la edad de jubilación judicial, así como las cuestiones procesales de la admisibilidad de las acciones preventivas de tipo declaratorio u omisional, y de la compulsa judicial de los conceptos legales dudosos (problemas todos ellos a los que ya se ha hecho referencia en las lineas que anteceden), además de la importancia de la modificación de la situación de hecho o de derecho durante el proceso, del objeto del litigio y de la cosa juzgada material. Todos estos problemas quedan en manos de la doctrina y de la jurisprudencia para su oportuna elucidación. Asimismo, el concepto de acto administrativo, que emplea la ley en numerosas disposiciones, no aparece - como ya hemos apuntado más arribalo suficientemente precisado. Es también tarea propia de la doctrina y de la jurisprudencia delimitarlo y precisarlo progresivamente, atendiendo a las determinaciones conceptuales vertidas en leyes anteriores, a las exigencias de orden jurídico-constitucional (articulo 19 , párrafo 4 de la Ley Fundamental) y a la finalidad propia del procedimiento. Por último, indicaremos que la Ley no regula en todos sus pormenores el procedimiento ante los Tribunales de la jurisdicción administrativa común. Para ampliar y completar esta regulación hace referencia, en numerosos preceptos, a otras disposiciones de Derecho federal y local. A este respecto se citan de manera preponderante los preceptos de la Ley Orgánica del Poder Judicial y de la Ley de Enjulciamiento Civil, a las cuales remite la Ley de modo genérico o bien en casos especiales y concretos (parágrafo 173).

Resumiendo: puede afirmarse que la nueva Ley unificadora sobre jurisdicción administrativa ha significado un progreso sustancial frente al diseminado $\mathrm{y}$ disperso derecho vigente hasta la fecha. $\mathrm{Y}$ esto resulta tanto más beneficioso cuanto que la evolución del Estado hacia el Estado de bienestar (Wohlfahrtstaat) y de previsión no sólo no ha disminuído la importancia de la jurisdicción administrativa, sino que ha ventdo a aumentarla. La múltiple dependencia en que se halla hoy el individuo de las prestaciones concedidas por el Estado, y con ello de las autoridades encargadas de su administración, resultaría insoportable en un Estado de Derecho si el particular no pudiese disponer de una tutela jurídica asegurada por Tribunales independientes frente a las resoluciones y actos de la autoridad administrativa. La implantación del principio de la generalidad y la ampliación de la tutela jurídica administrativo-judicial corresponden por ello a la evolución del concepto del Estado que inició su transformación al término de la primera guerra mundial. 